OPEN ACCESS

Edited by: Igor B. Mekjavic, Jožef Stefan Institute, Slovenia

Reviewed by: Matthew Cramer, Institute for Exercise and Environmental Medicine,

United States Naoto Fujii,

University of Tsukuba, Japan

*Correspondence:

Jose A. Rodríguez-Marroyo j.marroyo@unileon.es

Specialty section:

This article was submitted to Exercise Physiology,

a section of the journal

Frontiers in Physiology

Received: 23 May 2017 Accepted: 09 August 2017 Published: 24 August 2017

Citation:

Carballo-Leyenda B, Villa JG, López-Satué $J$ and

Rodríguez-Marroyo JA (2017) Impact of Different Personal Protective Clothing on Wildland Firefighters Physiological Strain

Front. Physiol. 8:618. doi: 10.3389/fphys.2017.00618

\section{Impact of Different Personal Protective Clothing on Wildland Firefighters' Physiological Strain}

\author{
Belén Carballo-Leyenda ${ }^{1}$, José G. Villa ${ }^{1}$, Jorge López-Satué ${ }^{2}$ and \\ Jose A. Rodríguez-Marroyo ${ }^{1 *}$ \\ ${ }^{1}$ Department of Physical Education and Sports, Institute of Biomedicine, University of León, León, Spain, ${ }^{2}$ Empresa de \\ Transformación Agraria, Madrid, Spain
}

Wildfire firefighting is an extremely demanding occupation performed under hot environment. The use of personal protective clothing (PPC) is needed to protect subjects from the thermal exposure. However, the additional use of PPC may increase the wildland firefighters' physiological strain, and consequently limit their performance. The aim of this study was to analyze the effect of four different PPC on the physiological strain of wildland firefighters under moderate conditions $\left(30^{\circ} \mathrm{C}\right.$ and $\left.30 \% \mathrm{RH}\right)$. Eight active and healthy wildland firefighters performed a submaximal walking test wearing a traditional short sports gear and 4 different PPC. The materials combination (viscose, Nomex, Kevlar, P-140 and fire resistant cotton) used during the PPC manufacturing process was different. During all tests, to simulate a real scenario subjects wore a backpack pump (20 kg). Heart rate, respiratory gas exchange, gastrointestinal temperature, blood lactate concentration, perceived exertion and temperature and humidity underneath the PPC were recorded throughout tests. Additionally, parameters of heat balance were estimated. Wearing a PPC did not cause a significant increase in the subjects' physiological response. The gastrointestinal temperature increment, the relative humidity of the microclimate underneath the PPC, the sweat residue in PPC, the sweat efficiency, the dry heat exchange and the total clothing insulation were significantly affected according to the PPC fabric composition. These results suggest that the PPC composition affect the moisture management. This might be taken into account to increase the wildland firefighters' protection in real situations, when they have to work close to the flames.

Keywords: heat stress, thermal strain, thermophysiological response, core temperature, protective clothing

\section{INTRODUCTION}

Wildfire firefighting is an extremely demanding occupation (Ruby et al., 2002; Cuddy et al., 2015) that mainly takes place during the summer season. Activities performed during wildfire suppression require work with hand tools of different weight (3-20 kg) (Rodríguez-Marroyo et al., 2012) and they are usually performed under difficult conditions, such as inhaling smoke (Wegesser et al., 2009), working on steep terrain (Brotherhood et al., 1997) and in hot environments (Raimundo and Figueiredo, 2009; Rodríguez-Marroyo et al., 2012). Collectively, all these circumstances contribute to the high physiological strain observed during wildfires suppression (Rodríguez-Marroyo et al., 2012). 
Performing demanding tasks in hot environments is associated with an increased heat stress (Gonzalez-Alonso et al., 1999; Cheuvront et al., 2010). The additional use of personal protective clothing (PPC) may increase the wildland firefighters' thermal strain (Bruce-Low et al., 2007), and consequently limit their performance (Selkirk and McLellan, 2004; Taylor et al., 2012). PPC affects the heat-dissipating thermoregulatory mechanisms since they limit the heat loss and vapor transfer between the skin and the environment (Holmér, 2006). Nonetheless, PPC protects subjects from a wide variety of work-related hazards mainly from the thermal exposure (Nayak et al., 2014). They are manufactured according to security standards (ISO, 2003), where technical requirements of the fabrics are specified. However, this certification does not take into account the process of making the suits, which does not allow to directly extrapolate the response that these fabrics will induce in thermoregulation once they constitute a complete suit and this is carried by a person. The design and materials combination during the PPC manufacturing process may affect their performance on the thermoregulatory response (Havenith and Heus, 2004). The degree of PPC's thermal and vapor insulation will depend on the clothing thickness, trapped air layers and fiber characteristics (e.g., weave, coatings and membranes) (Havenith, 2002).

It seems clear that PPCs have to provide a specific protection and minimize subjects' thermal and physiological strain in order to avoid injuries and not limit their performance. There is considerable research regarding the effect of different PPC on the thermoregulatory response of structural firefighters (Sköldström, 1987; Smith and Petruzzello, 1998; Selkirk and McLellan, 2004; Holmér et al., 2006; Bruce-Low et al., 2007), chemical (Wen et al., 2015), military (Montain et al., 1994) and industry (Poirier et al., 2015) situations. This contrasts with the paucity of studies carried out with wildland firefighters. To the best of our knowledge, an earlier study had analyzed wildland firefighters' response to different PPC (Budd et al., 1997). Budd et al. (1997) compared two different PPC, one thicker and more encapsulated vs. a lighter and more open one. However, these authors did not assess the physiological impact of the PPC on wildland firefighters vs. a control experimental condition (e.g., sports gear). Therefore, the aim of this study was to analyze the effect of four different PPC, according to their fabric composition, on the physiological strain of wildland firefighters during moderate exercise intensity (i.e., $250 \mathrm{~W} \cdot \mathrm{m}^{-2}$ ) and under warm environmental conditions (i.e., $\left.30^{\circ} \mathrm{C}, 30 \% \mathrm{RH}\right)$.

\section{METHODS}

\section{Participants}

Eight active and healthy male wildland firefighters (mean \pm SD; age $30.8 \pm 8.4$ years, height $1.79 \pm 0.06 \mathrm{~m}$, body mass $76.9 \pm$ $10.8 \mathrm{~kg}$, maximal oxygen uptake $55.4 \pm 9.1 \mathrm{ml} \cdot \mathrm{kg}^{-1} \cdot \mathrm{min}^{-1}$, and body surface area $1.9 \pm 0.2 \mathrm{~m}^{2}$ ) were involved in this study. Subjects performed endurance exercise (45-60 min/training session) three times per week as part of their scheduled training. Written informed consent was obtained from the volunteers before starting the study. The study protocol was developed in accordance with the guidelines of the Helsinki Conference for research on human subjects and was approved by the Ethics Committee of the University of León, Spain.

\section{Experimental Design}

Each subject performed six trials over six separate testing sessions. Trials were separated by at least $48 \mathrm{~h}$, during which participants were asked to refrain from strenuous exercise. The first trial was a maximal incremental test to determine subjects' characteristics and their exercise capacity (Bruce, 1971). During the second to sixth trial, subjects performed, in a balanced Latin Square design, a 120 min submaximal test wearing a traditional short sports gear (i.e., shorts, and cotton t-shirt, underwear and socks) and 4 different PPC. All PPC adhered to (ISO, 2003) and are currently used by Spanish wildland firefighters. Although wildland firefighters' personal protective equipment includes items such as helmet, gloves, goggles and mid-calf leather boots, they were not used during the trials. The same clothing (i.e., cotton t-shirt, underwear and socks) was worn under PPC during all trials. Garments' specifications are showed in Table 1. During all tests, to simulate a real scenario subjects wore a backpack pump (20 kg), which is routinely used during wildfire firefighting (Rodríguez-Marroyo et al., 2012). In addition, the same running shoes (250-300 g per shoe) were used in every testing session.

\section{Tests Protocol}

All tests were performed on a treadmill ( $\mathrm{h} / \mathrm{p} / \mathrm{cosmos}$ pulsar, $\mathrm{h} / \mathrm{p} /$ cosmos sports and medical GMBH, Nussdorf-Traunstein, Germany). Each test was preceded by a 10 min warm-up at $60 \%$ of maximum heart rate $\left(8-10 \mathrm{~km} \cdot \mathrm{h}^{-1}\right)$ and $5 \mathrm{~min}$ of stretching. The maximal test was performed according to the protocol described by Bruce (1971). The test started with a speed of $2.5 \mathrm{~km} \cdot \mathrm{h}^{-1}$ and a slope of $10 \%$. The speed and grade were incremented every 3 min until volitional exhaustion.

The submaximal tests were performed at the same time of the day (between 12:00 and 16:00 h) in a laboratory under climatecontrolled conditions. Air temperature and relative humidity were maintained at $30^{\circ} \mathrm{C}$ and $30 \%$, respectively, simulating those analyzed in real wildland fires (Rodríguez-Marroyo et al., 2012). The protocol consisted of 6 sets of walking at $6 \mathrm{~km} \cdot \mathrm{h}^{-1}$ and a slope of $1 \%$ with $5 \mathrm{~min}$ passive rest periods in between. Each set duration was $15 \mathrm{~min}$, except for the first set that was $20 \mathrm{~min}$, so the total test length was $120 \mathrm{~min}$. During recovery periods, $0.15 \mathrm{ml} \cdot \mathrm{kg}^{-1}$ of water every $1 \mathrm{~min}$ of exercise at $15^{\circ} \mathrm{C}$ (Selkirk and McLellan, 2004) was administered to prevent that subjects' dehydration limited the sweat rate (Cheuvront et al., 2010). The protocol used in this study was based on previous studies (Selkirk and McLellan, 2004) and the selected speed allowed subjects to perform an exercise intensity between 60 and $70 \%$ of the maximal heart rate, which simulates wildland firefighters' working conditions (Rodríguez-Marroyo et al., 2012).

\section{Measurements}

ECG monitoring (Medisoft Ergocard, Medisoft Group, Sorinnes, Belgium) was performed throughout the maximal test to detect heart problems. During both maximal and submaximal tests, the heart rate $(\mathrm{HR})$ response and the respiratory gas exchange 
TABLE 1 | Personal protective clothing (PPC) characteristics.

\begin{tabular}{|c|c|c|c|c|c|}
\hline \multicolumn{2}{|l|}{ Layer } & $\begin{array}{l}\text { PPC\#1 } \\
\text { Single }\end{array}$ & $\begin{array}{c}\text { PPC\#2 } \\
\text { Reflective double layer on shoulders }\end{array}$ & $\begin{array}{l}\text { PPC\#3 } \\
\text { Single }\end{array}$ & $\begin{array}{l}\text { PPC\#4 } \\
\text { Single }\end{array}$ \\
\hline & Nomex (\%) & 30 & 30 & 34 & \\
\hline & Kevlar (\%) & 5 & 5 & 8 & \\
\hline & P-140 (\%) & & & 2 & \\
\hline \multicolumn{2}{|l|}{ Mass (g) } & 1,460 & 1,560 & 1,440 & 1,000 \\
\hline \multicolumn{2}{|c|}{ Surface mass $\left(\mathrm{g} \cdot \mathrm{m}^{-2}\right)$} & 270 & 270 & 225 & 310 \\
\hline \multicolumn{2}{|c|}{ Total mass $(\mathrm{kg})^{\star}$} & $79.6 \pm 7.4$ & $79.5 \pm 6.6$ & $79.7 \pm 7.0$ & $78.1 \pm 6.5$ \\
\hline \multicolumn{2}{|c|}{ Fabric thermal resistance $\left(\mathrm{m}^{2} \cdot \mathrm{K} \cdot \mathrm{W}^{-1}\right)$} & 0.0192 & 0.0192 & 0.0213 & 0.0260 \\
\hline \multicolumn{2}{|c|}{ Fabric evaporative resistance $\left(\mathrm{m}^{2} \cdot \mathrm{Pa} \mathrm{W}^{-1}\right)$} & 3.79 & 3.79 & 3.45 & 3.51 \\
\hline
\end{tabular}

FR, fire resistant. *Subjects mass while wearing the PPC.

was continuously measured every 5-s (RS800, Polar Electro Oy, Kempele, Finlandia) and breath-by-breath (Medisoft Ergocard, Medisoft Group, Sorinnes, Belgium), respectively. $\mathrm{VO}_{2 \max }$ was accepted as the highest 30-s moving average.

Gastrointestinal temperature was recorded throughout submaximal trials using a Jonah intestinal temperature capsule (VitalSense, Phillips Respironics, Bend, OR, USA) which was ingested at least $8 \mathrm{~h}$ before the beginning of trials (Wen et al., 2015). Temperature and humidity underneath the PPC were also measured (Termoregister TR-72U, T and D, Japan). Data logger was placed at the sternum level, between the cotton t-shirt and PPC. Temperature and humidity data, as well as HR and $\mathrm{VO}_{2}$ data from the last $5 \mathrm{~min}$ of each submaximal exercise stage, were considered representative measurements of each stage. The gastrointestinal temperature and HR data were used to calculate the physiological strain index (PSI) throughout the trials according to Tikuisis et al. (2002).

Capillary blood samples were taken from a previously hyperemized earlobe to measure blood lactate concentration (Lactate Scout, Senslab, Leipzig, Germany) after the end of each submaximal stage. During the last 30 -s of each exercise stage, the Rating of Perceived Exertion (RPE) was recorded using the Borg scale (6-20) (Borg, 1982). The scale was explained and administered by the same researcher, asking about subjects' perceived exertion using the same question. A cue card was located in front of subjects to allow immediate reference to the scale. Additionally, subjects' moisture sensation was recorded at the end of each trial, using a categorical scale (19) (Havenith and Heus, 2004). Verbal anchors associated with 1 and 9 were identified with slightly moist and totally soaked, respectively.

Subjects, in underwear, and each clothing component were separately weighted (50K150, COBOS, Hospitalet de Llobregat, Barcelona, Spain) at the beginning and the end of each submaximal trial. This allows calculating the total sweat production, sweat residue and sweat evaporation (Havenith and Heus, 2004; Kofler et al., 2015). Total sweat was corrected for the fluid intake. Water loss through breathing was neglected and was assumed to be similar between trials (Saunders et al., 2005).
Finally, the sweat efficiency was calculated as the ratio between sweat evaporation and total sweat (Havenith and Heus, 2004).

Heat balance of the body was estimated using a method of partitional calorimetry summarized in equation 1 (Bröde et al., 2008):

$$
\mathrm{S}=\mathrm{M}-\mathrm{W} \pm \mathrm{DRY}-\mathrm{E}_{\mathrm{sk}}-\mathrm{RES}
$$

Components of the equation were heat storage (S), metabolic energy production $(\mathrm{M})$, effective mechanical work (W), heat loss through evaporative and convective heat exchange via respiration $\left(\mathrm{RES}=\mathrm{E}_{\mathrm{res}}+\mathrm{C}_{\mathrm{res}}\right)$, evaporative heat loss $\left(\mathrm{E}_{\mathrm{sk}}\right)$, and dry heat loss $(\mathrm{DRY}=\mathrm{C}+\mathrm{R}+\mathrm{K})$. All heat balance parameters were calculated in $\mathrm{W} \cdot \mathrm{m}^{-2}$. The components were estimated and served only to substantiate the results.

The rate of metabolic heat production was calculated from measured respiratory quotient $(\mathrm{RQ})$ and $\mathrm{VO}_{2}\left(\mathrm{~L} \cdot \mathrm{min}^{-1}\right)$ and the body surface area $\left(\mathrm{A}_{\mathrm{D}} ; \mathrm{m}^{2}\right)$ calculated using DuBois formula (DuBois and DuBois, 1916), as shown below in Equation (2) (Gagge and Gonzalez, 1996):

$$
\mathrm{M}=[0.23(\mathrm{RQ})+0.77] \times 5.873 \times \mathrm{VO}_{2} \times\left(60 / \mathrm{A}_{\mathrm{D}}\right)
$$

Effective mechanical work was calculated using acceleration due to gravity $\left(9.8 \mathrm{~m} \cdot \mathrm{s}^{-2}\right)$, the dressed mass of participants $\left(\mathrm{m}_{\mathrm{d}} ; \mathrm{kg}\right)$, the speed $\left(v ; \mathrm{m} \cdot \mathrm{s}^{-1}\right)$ and the grade fraction $(\mathrm{F})$ of the treadmill and $A_{D}$, using Equation (3) (McLellan et al., 1996):

$$
\mathrm{W}=9.8 \times \mathrm{m}_{\mathrm{d}} \times \mathrm{v} \times \mathrm{F} \times \mathrm{A}_{\mathrm{D}}^{-1}
$$

The respiratory heat loss components $\mathrm{C}_{\text {res }}$ and $\mathrm{E}_{\text {res }}$ were calculated using Equations (4) and (5), respectively (Bröde et al., 2008):

$\mathrm{C}_{\text {res }}=1.516 \times 10^{-3} \times \mathrm{M} \times\left(28.56-0.641 \times \mathrm{P}_{\mathrm{a}}-0.885 \times \mathrm{T}_{\mathrm{a}}\right.$

$\mathrm{E}_{\text {res }}=1.27 \times 10^{-3} \times \mathrm{M} \times\left(59.34-11.63 \times \mathrm{P}_{\mathrm{a}}+0.53 \times \mathrm{T}_{\mathrm{a}}\right.$ 
where $\mathrm{P}_{\mathrm{a}}$ is the atmospheric pressure in Pascals, $\mathrm{T}_{\mathrm{a}}$ is the ambient temperature in ${ }^{\circ} \mathrm{C}$ and $\mathrm{M}$ is the rate of metabolic heat production in $\mathrm{W} \cdot \mathrm{m}^{-2}$, calculated with Equation (3).

$\mathrm{S}$ was calculated as $\left(\Delta \mathrm{T}_{\mathrm{b}} \times \Delta \mathrm{t}^{-1}\right) \times \mathrm{BM} \times \mathrm{A}_{\mathrm{D}}^{-1} \times \mathrm{c}_{\mathrm{p}} \cdot \Delta \mathrm{T}_{\mathrm{b}}$ $\times \Delta \mathrm{t}^{-1}$ in ${ }^{\circ} \mathrm{C} \cdot \mathrm{s}^{-1}$ was described as the rate of change of body temperature accounting for tests duration $(s), c_{p}$ represented the specific heat of body tissue $(3,480 \mathrm{~J})$ and $\mathrm{BM}$, body mass in $\mathrm{kg}$. As skin temperature $\left(\mathrm{T}_{\text {skin }}\right)$ was not measured, the chest temperature $\left(\mathrm{T}_{\text {chest }}\right)$ of the microclimate underneath PPC served as an indirect marker of $\mathrm{T}_{\text {skin }}$ (Kofler et al., 2015). Mean body temperature $\left(\mathrm{T}_{\mathrm{b}}\right)$ in ${ }^{\circ} \mathrm{C}$ was estimated by $4: 1$ ratio of gastrointestinal temperature $\left(\mathrm{T}_{\mathrm{GI}}\right)$ and $\mathrm{T}_{\text {chest }}$ as $\mathrm{T}_{\mathrm{b}}=0.8 \times \mathrm{T}_{\mathrm{GI}}+0.2 \times \mathrm{T}_{\text {chest }}$, recommended for warm environments (Bröde et al., 2008).

$E_{\text {sk }}$ corrected for respiratory loss was estimated as $\lambda \times\left(m_{e} \times\right.$ $\left.\Delta \mathrm{t}^{-1}\right) \times \mathrm{A}_{\mathrm{D}}^{-1}-\mathrm{E}_{\text {res. }}$. Where $\mathrm{m}_{\mathrm{e}}$ is the evaporative sweat loss (g) with $\Delta$ t denoting measurement time (s), $\lambda$ the enthalpy of evaporation $\left(2,430 \mathrm{~J} \cdot \mathrm{g}^{-1}\right)$ and $E_{\text {res }}$ is the respiratory heat evaporation calculated using Equation (5). DRY resulted by solving the heat balance equation with the other known components using Equation (6) (Bröde et al., 2008):

$$
\mathrm{DRY}=\mathrm{M}-W-\mathrm{E}_{\mathrm{sk}}-\mathrm{RES}-\mathrm{S}
$$

Additionally, total insulation $\left(\mathrm{I}_{\mathrm{t}}\right)$ of clothing was estimated through the equation $\left(\mathrm{T}_{\text {chest }}-\mathrm{T}_{\mathrm{a}}\right) \times \mathrm{DRY}^{-1}$. This estimation was also less precise, like the calculation of $S$ because of using $\mathrm{T}_{\text {chest }}$ instead of $\mathrm{T}_{\text {skin }}$ (Kofler et al., 2015).

\section{Statistical Analysis}

The results are expressed as mean \pm standard deviation $(S D)$. The assumption of normality was verified using the ShapiroWilk's test. The variables analyzed throughout the submaximal trials $\left(\mathrm{VO}_{2}\right.$, ventilation, $\mathrm{HR}$, blood lactate concentration, gastrointestinal temperature, PSI, micro environment temperature, relative humidity, and RPE) were compared using a repeated two-way ANOVA with two within-subject factors (clothing and time). A one-way ANOVA with repeated measures was applied to calculate differences between trials when subjects' gastrointestinal temperature increment, moisture sensation, and the different parameters of heat balance and sweat were studied. When a significant $F$-value was found, Bonferroni's test was used to establish significant differences between means. The assumption of sphericity was checked using the Mauchly's test when this assumption was violated the Greenhouse-Geisser adjustment was performed. Values of $p<0.05$ were considered statistically significant. SPSS V.19.0 statistical software (SPSS Inc., Chicago, Illinois, USA) was used.

\section{RESULTS}

The interaction between clothing condition and time was not significant for $\mathrm{VO}_{2}$, ventilation, $\mathrm{HR}$, blood lactate, gastrointestinal temperature, PSI, temperature underneath the PPC, and RPE (Figure 1). The mean values analyzed during the trials were: $1.5 \pm 0.3 \mathrm{~L} \cdot \mathrm{min}^{-1}, 48.4 \pm 8.5 \mathrm{~L} \cdot \mathrm{min}^{-1}, 114 \pm 15$ $\mathrm{bpm}, 1.5 \pm 0.2 \mathrm{mmol} \cdot \mathrm{L}^{-1}, 37.4 \pm 0.5^{\circ} \mathrm{C}, 3.2 \pm 0.7$ units, $32.7 \pm$ $1.2^{\circ} \mathrm{C}$ and $10.7 \pm 2.0$, respectively. Likewise during the trials no significant main effect of time condition was present on these variables (Figure 1). However, the gastrointestinal temperature increment was significantly higher with PPC\#3 $\left(0.7 \pm 0.3^{\circ} \mathrm{C}\right)$ than those analyzed with the others PPC $(0.2 \pm 0.3,0.2 \pm 0.5$ and $0.2 \pm 0.3^{\circ} \mathrm{C}$ for PPC\#1, PPC\#2, PPC\#4, respectively) and sports gear $\left(0.3 \pm 0.3^{\circ} \mathrm{C}\right)$.

The relative humidity of the microclimate underneath the PPC was higher $(p<0.05)$ in PPC\#2, PPC\#3 than PPC\#4 $(81.2 \pm$ 4.7 and $77.7 \pm 5.0$ vs. $71.7 \pm 4.9 \%)$. From the 60 th minute of trail, the lowest $(p<0.05)$ values were analyzed in PPC\#4 (Figure 2). The humidity data increased more rapidly during the first part of the trials (i.e., 0-60 min), and it slowed during the second hour (i.e., 60-120 min) (Figure 2). Collectively, significant differences $(p<0.05)$ between the data analyzed at $5-20 \mathrm{~min}(\sim 63 \% \mathrm{RH})$ vs. 60-120 $\min (\sim 84 \% \mathrm{RH})$ were found.

The total sweat production was similar in all PCC and when subject wore the sports gear (Table 2). The sweat residue in underwear was similar in all tests. However, the sweat residue in PPC\# 1 was the lowest $(p<0.05)$, and as a consequence the sweat efficiency of PPC\#1 was the highest $(p<0.05)$ of all PCC analyzed in this study. Indeed, the lower $(p<0.05)$ subjects' moisture sensation was analyzed with the PPC\#1 $(5.6 \pm 0.3,7.6 \pm 0.9$, $7.0 \pm 0.6$, and $8.2 \pm 0.5$ for PPC\#1, PPC\#2, PPC\#3, and PPC\#4, respectively). The lowest value was obtained when subjects wore the sports gear $(3.8 \pm 1.0)$.

Estimated parameters of heat balance are showed in Table 3. The dry heat exchange of PPC\#2 and PPC\#3 was significantly $(p<0.05)$ different from PPC\#4. Total clothing insulation was significantly $(p<0.05)$ lower in PPC\#1.

\section{DISCUSSION}

The aim of this study was to investigate the effect of different PPC on the physiological strain of wildland firefighters. Contrary to our expectations, no significant differences in the cardiorespiratory variables analyzed between the ensembles were found (Figure 1). Previous studies (Baker et al., 2000; Dorman and Havenith, 2009; Wen et al., 2015) reported an increase of $10-20 \%$ in the physiological response (e.g., $\mathrm{VO}_{2}$ ) with the use of different PPC. Other studies (Sköldström, 1987; Taylor et al., 2012; Lee et al., 2014) analyzed a greater increase $(>20 \%)$ in structure firefighters when they used the self-contained breathing apparatus, due to the rise in weight (10-20 kg) of the ensemble (Lee et al., 2014). The mean increase observed in this study when wearing the PPC was lower, $\sim 12 \%$. Possibly, this was consequence of the lower thermal insulation of the PPC used by wildland firefighters $\left(\sim 0.23 \mathrm{~m}^{2} \cdot \mathrm{K} \cdot \mathrm{W}^{-1}\right)$ (Raimundo and Figueiredo, 2009) vs. those of structure firefighters $\left(0.47 \mathrm{~m}^{2} \cdot \mathrm{K} \cdot \mathrm{W}^{-1}\right)$ (Holmér et al., 2006), which have allowed for a greater heat dissipation. Additionally, in this study subjects performed the trials without gloves, helmet and boots. This conditioned their thermoregulatory response by increasing the body surface exposed to the environment and thus facilitate the heat loss (Holmér, 2006; Lee et al., 2014). Lee et al. (2014) did not find significant differences in the $\mathrm{VO}_{2}$ and $\mathrm{HR}$ of structure firefighters when they wore the 

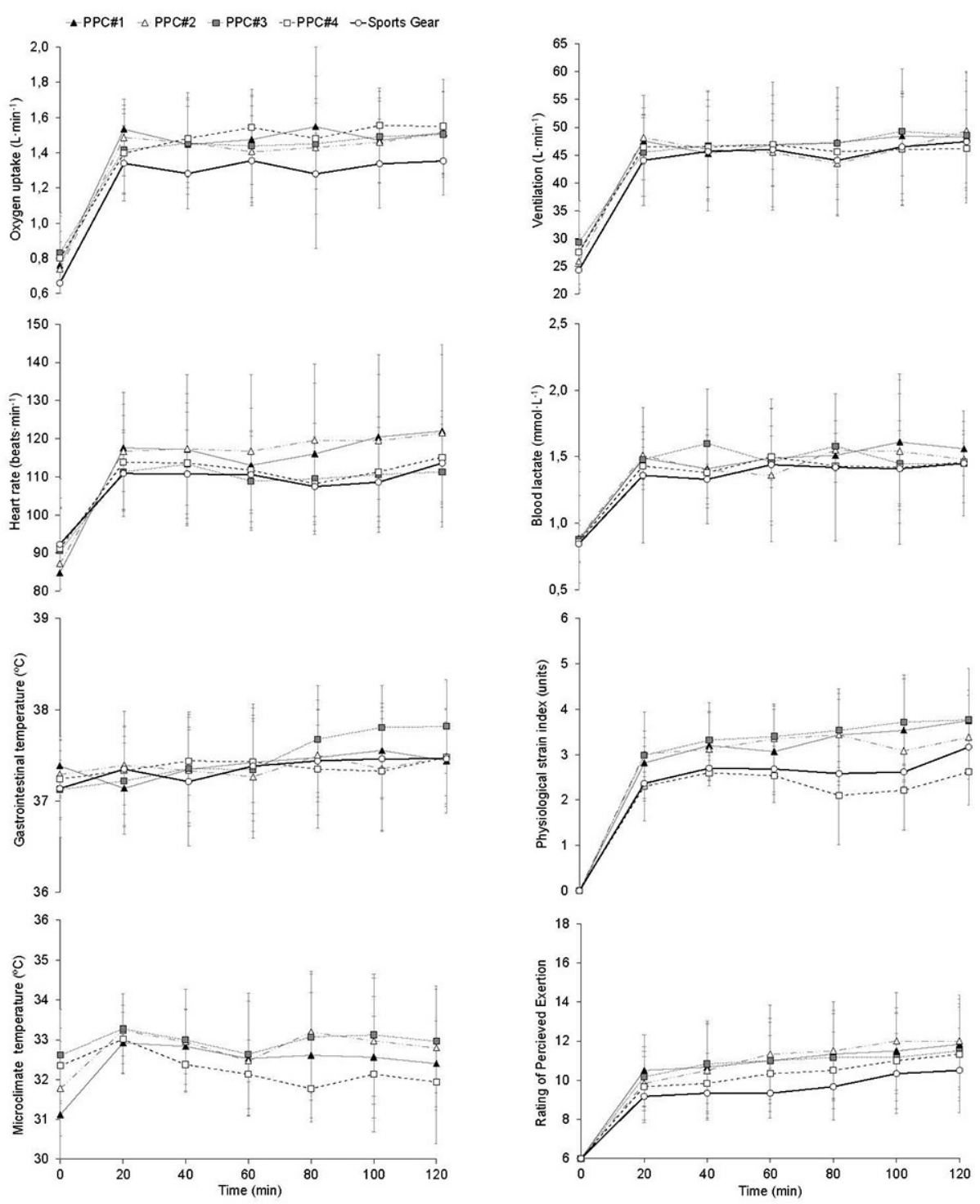

FIGURE 1 | Comparative responses of oxygen uptake, ventilation, heart rate, blood lactate concentration, gastrointestinal temperature, physiological strain index, temperature of the microclimate underneath the personal protective clothing (PPC), and rating of perceived exertion during the different trials.

protective equipment without gloves, helmet and boots vs. a sports gear.

The limited weight difference between the ensembles studied might have influenced in the physiological variables pattern. It has been reported that more than half of the increase in the metabolic rate is due to the PPC weight (Dorman and Havenith, 2009). Indeed, no differences in the cardiorespiratory response or RPE have been found when wearing a light-weight workwear compared to a control condition (Kofler et al., 2015). On the other hand, the subjects' aerobic fitness might attenuate the $\mathrm{HR}, \mathrm{VO}_{2}$, gastrointestinal temperature and $\mathrm{RPE}$ response in the trials where the PPC were worn (Selkirk and McLellan, 2001). The $\mathrm{VO}_{2 \max }$ analyzed in this study was $\sim 28 \%$ higher than that previously described $\left(\sim 43 \mathrm{ml} \cdot \mathrm{kg}^{-1} \cdot \mathrm{min}^{-1}\right)$ in wildland firefighters (Phillips et al., 2011). Subjects with greater fitness present higher tolerance to effort under conditions of thermal stress wearing a PPC (Selkirk and McLellan, 2001).

Wearing a PPC in hot environments has been associated with an increased body temperature (Smith and Petruzzello, 1998; Bruce-Low et al., 2007). However, in moderate environmental conditions, such as those maintained in this study, no significant differences in gastrointestinal temperature were observed (Figure 1), despite the greater temperature elevation analyzed throughout the trial in PPC\#3. Collectively, this findings are in agreement with those obtained in previous research performed under similar conditions with light-weight PPC (Wang et al., 2013; Kofler et al., 2015). Subjects' gastrointestinal temperature was below $38^{\circ} \mathrm{C}$ during all trials. This value has been 
informed as a limiting factor of performance during exercise in heat (Gonzalez-Alonso et al., 1999). Possibly, the temperature remained stable during the trials performed with PPC by the increase of the cardiovascular stress. In fact, the mean HR was $\sim 5 \%$ higher $(p>0.05)$ when subjects wore the PPC. It may be speculated that this was due to the increase of the cutaneous circulation in order to favor the heat dissipation (Cheuvront et al., 2010). The HR pattern might also be reflecting the greater metabolic rate related to the weight difference between PPC and

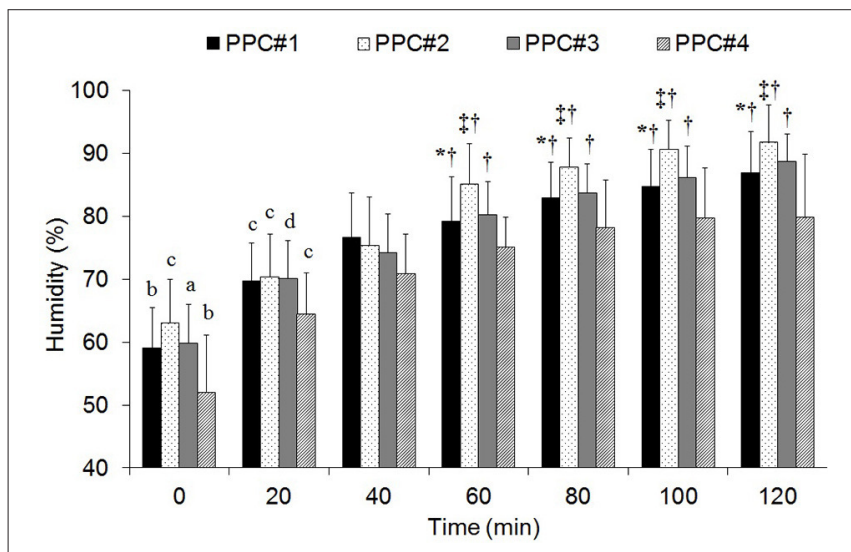

FIGURE 2 | Relative humidity pattern recorded during the trials performed with the different personal protective clothing (PPC). *Differences with PPC\#2 $(p<0.05)$. ${ }^{\ddagger}$ Differences with PPC\#3 $(p<0.05)$. ${ }^{\dagger}$ Differences with PPC\#4 $(p<$ 0.05). ${ }^{a}$ Differences with $20-120$ min $(p<0.05)$. ${ }^{b}$ Differences with $40-120$ min $(p<0.05)$. ${ }^{c}$ Differences with 60-120 min $(p<0.05)$. dDifferences with $100-120 \min (p<0.05)$. the sports gear configuration (Dorman and Havenith, 2009). The $\mathrm{VO}_{2}$ was higher $(p>0.05)$ by $\sim 200 \mathrm{ml} \cdot \mathrm{min}^{-1}$ with vs. without PPC (Figure 1).

Globally, we analyzed a difference of $\sim 2.5^{\circ} \mathrm{C}$ between the temperature of the microclimate underneath the PPC and the outside temperature. However, the mean temperature of the microclimate of PPC\#2 and PPC\#3 was $0.8^{\circ} \mathrm{C}$ higher $(p>$ $0.05)$ than those analyzed in the other PPC. This difference accentuated more after the first $60 \mathrm{~min}$ of exercise (Figure 1). This fact might be related with the lower dry heat exchange observed in PPC\#2 and PPC\#3 (Table 3) due to the thickness and air porosity of these garments (Havenith et al., 2011). The studied PPC are manufactured with highly heat-resistant fabrics (i.e., Nomex and Kevlar) mixed with fire resistant viscose, which lends PPC a greater air permeability and comfort (Yoo and Barker, 2005). The PPC\#3 composition had a 10\% less of viscose (Table 1), so its porosity and air permeability was reduced, which might negatively affect the dry heat exchange. The PPC\#2 had a double layer in the shoulders area which increases its thickness and thermal insulation, thus limiting the dry heat exchange (Holmér, 2006). The reduced dry heat exchange and evaporative heat loss obtained in PPC\#3 would explain the higher increase in gastrointestinal temperature observed in this garment $\left(0.7^{\circ} \mathrm{C}\right)$ compared to the other ensembles $\left(\sim 0.3^{\circ} \mathrm{C}\right)$. No significant differences were found in evaporative heat transfer between PPC (Table 3). Probably this was related to the variability of the evaporated sweat calculation. However, the higher relative humidity observed underneath PPC\#2 and PPC\#3 and the lower magnitude of evaporative heat loss, suggests that the evaporative heat transfer might be decreased in both garments. Several studies have related the higher humidity in

TABLE 2 | Sweat measurements analyzed in this study (mean $\pm S D$ ).

\begin{tabular}{|c|c|c|c|c|c|}
\hline & PPC\#1 & PPC\#2 & PPC\#3 & PPC\#4 & Sports gear \\
\hline Total sweat production (g) & $1,910 \pm 360$ & $2,342 \pm 450$ & $2,110 \pm 390$ & $1,968 \pm 370$ & $1,925 \pm 447$ \\
\hline Sweat residue in underwear (g) & $367 \pm 53$ & $368 \pm 70$ & $361 \pm 54$ & $409 \pm 61$ & $335 \pm 156$ \\
\hline Sweat evaporation (g) & $1,514 \pm 327$ & $1,395 \pm 161$ & $1,274 \pm 268$ & $1,189 \pm 338^{\$}$ & $1,609 \pm 251$ \\
\hline Sweat efficiency (\%) & $74 \pm 5^{\star \ddagger 十 \$}$ & $61 \pm 7^{\$}$ & $59 \pm 5^{\$}$ & $58 \pm 9$ & $84 \pm 8$ \\
\hline
\end{tabular}

PPC, personal protective clothing. ${ }^{*}$ Differences with PPC\#2 $(p<0.05) .{ }^{\ddagger}$ Differences with PPC\#3 $(p<0.05) .{ }^{\dagger}$ Differences with PPC\#4 $(p<0.05) .{ }^{\$}$ Differences with Sports Gear $(p<$ 0.05).

TABLE 3 | Estimated parameters of heat balance analysis (mean $\pm S D$ ).

\begin{tabular}{|c|c|c|c|c|}
\hline & PPC\#1 & PPC\#2 & PPC\#3 & PPC\#4 \\
\hline Heat storage $\left(\mathrm{W} \cdot \mathrm{m}^{-2}\right)$ & $4.5 \pm 7.5$ & $5.5 \pm 14.0$ & $8.1 \pm 6.3$ & $3.8 \pm 6.0$ \\
\hline Metabolic heat production $\left(\mathrm{W} \cdot \mathrm{m}^{-2}\right)$ & $250.5 \pm 23.7$ & $238.4 \pm 26.1$ & $243.2 \pm 34.9$ & $248.1 \pm 22.4$ \\
\hline Evaporative heat loss from skin $\left(\mathrm{W} \cdot \mathrm{m}^{-2}\right)$ & $251.5 \pm 48.1$ & $232.9 \pm 30.5$ & $210.9 \pm 42.9$ & $197.4 \pm 57.7$ \\
\hline Dry heat exchange $\left(\mathrm{W} \cdot \mathrm{m}^{-2}\right)$ & $15.8 \pm 15.7$ & $9.9 \pm 12.4^{\dagger}$ & $11.4 \pm 6.7^{\dagger}$ & $30.4 \pm 24.1$ \\
\hline
\end{tabular}

PPC, personal protective clothing. ${ }^{*}$ Differences with PPC\#2 $(p<0.05) .{ }^{\ddagger}$ Differences with PPC\#3 $(p<0.05) .{ }^{\dagger}$ Differences with PPC\#4 $(p<0.05)$. 
the microclimate with the lesser effective sweat evaporation (Kwon et al., 1998; Yoo and Barker, 2005; Bröde et al., 2008).

Although the lower relative humidity was analyzed in PPC\#4 (Figure 2), this did not lead to increased sweat evaporation. Indeed, the lower value was found in PPC\#4 (Table 2), obtaining a sweat efficiency similar to that of PPC\#2 and PPC\#3 ( $60 \%)$. The PPC\#4 composition (100\% cotton) and its greater thickness might have conditioned this pattern (Yoo and Barker, 2005). It has been reported the high capacity of cotton to retain moisture and its low evaporative efficiency when sweating is abundant (Kwon et al., 1998). These results confirm previous findings (Holmér, 1985), which highlight the high capacity of synthetic fibers (e.g., polyester, nylon, aramid) to transfer moisture quickly to the outside.

A higher sweat residue in the PPC might be beneficial to reduce the subjects' thermal strain since it would increase its thermal conductivity (Chen et al., 2003; Keiser and Rossi, 2008). In addition, the body movement when walking generates air currents that improve the heat exchange by increasing the ventilation (Qian and Fan, 2009). This forced convection due to movement might have helped the sweat evaporation throughout the trials (Lotens and Havenith, 1995; Bröde et al., 2008). This would avoid an excessive increase in the subjects' thermophysiological response at the end of the trials (Figure 1). However, a high sweat residue in PPC might be a disadvantage during wildfires suppressions. In these situations wildland firefighters are exposed to both radiant and convective heat (Raimundo and Figueiredo, 2009), with heat flows that oscillate between 0.42 and $8.37 \mathrm{~kW} \cdot \mathrm{m}^{-2}$ (Mäkinen, 2005). Under this circumstance the heat transfer would be reversed, passing the body to gain heat instead of dissipating it (Holmér, 2006).

\section{REFERENCES}

Baker, S. J., Grice, J., Roby, L., and Matthews, C. (2000). Cardiorespiratory and thermoregulatory response of working in fire-fighter protective clothing in a temperate environment. Ergonomics 43, 1350-1358. doi: 10.1080/001401300421798

Borg, G. A. V. (1982). Psychological bases of perceived exertion. Med. Sci. Sports Exerc. 14, 48-58.

Bröde, P., Havenith, G., Wang, X., Candas, V., den Hartog, E. A., Griefahn, B., et al. (2008). Non-evaporative effects of a wet mid layer on heat transfer through protective clothing. Eur. J. Appl. Physiol. 104, 341-349. doi: 10.1007/s00421-007-0629-y

Brotherhood, J. R., Budd, G. M., Hendrie, A. L., Jeffrey, S. E., Beasley, F. A., Costin, B. P., et al. (1997). Project Aquarius 3. effects of work rate on the productivity, energy expenditure, and physiological responses of men building fireline with a rakehoe in dry eucalypt forest. Int. J. Wildl. Fire 7, 87-98. doi: 10.1071/WF9970087

Bruce, R. A. (1971). Exercise testing of patients with coronary artery disease. Ann. Clin. Res. 3, 323-332.

Bruce-Low, S. S., Cotterrell, D., and Jones, G. E. (2007). Effect of wearing personal protective clothing and self-contained breathing apparatus on heart rate, temperature and oxygen consumption during stepping exercise and live fire training exercises. Ergonomics 50, 80-98. doi: 10.1080/00140130600980912

Budd, G. M., Brotherhood, J. R., Hendrie, A. L., Jeffery, S. E., Beasley, F. A., Costin, B. P., et al. (1997). Project Aquarius 13. the thermal burden of high insulation
Therefore, a high amount of moisture retained in the PPC might increase the risk of scalds (Keiser and Rossi, 2008). Taking into account the above, the PPC\#1 would be the most advantageous garment to protect the wildland firefighters in real scenarios, since it retained $\sim 65 \%$ less moisture content (Table 2 ). With this PPC subjects obtained the highest comfort (i.e., the lowest moisture sensation), which might affect the wildland firefighters' work efficiency and performance (Nayak et al., 2014).

In summary, no significant differences in the cardiorespiratory variables, blood lactate, gastrointestinal temperature, PSI and RPE between the different PPCs were found. However, our results suggest that the PPC composition affected the sweat efficiency and moisture sensation. The highest sweat efficiency and comfort were analyzed when subjects wore the PPC\#1. In addition, the lowest moisture content was found in this garment. This might mean more protection for wildland firefighters in real situations, when they have to work close to the flames.

\section{AUTHOR CONTRIBUTIONS}

Study Design: BC, JL, JV, JR. Data collection: BC, JL, JV. Data analyses: BC, JL, JV. Interpretation of the results: BC, JL, JV, JR. Manuscript writing: BC, JR. Approved the final manuscript version: BC, JL, JV, JR.

\section{FUNDING}

Financial support from Ministerio de Economía, Industria y Competitividad (Spain) grant (DEP2016-79762-P). In addition, the study has been funded by Empresa de Transformación Agraria, S.A. (TRAGSA). and encapsulation in wildland firefighters clothing. Int. J. Wildl. Fire 7, 207-218. doi: 10.1071/WF9970207

Chen, Y. S., Fan, J., and Zhang, W. (2003). Clothing thermal insulation during sweating. Text Res. J. 73, 152-157. doi: 10.1177/004051750307300210

Cheuvront, S. N., Kenefick, R. W., Montain, S. J., and Sawka, M. N. (2010). Mechanisms of aerobic performance impairment with heat stress and dehydration. J. Appl. Physiol. 109, 1989-1995. doi: 10.1152/japplphysiol.00367.2010

Cuddy, J. S., Sol, J. A., Hailes, W. S., and Ruby, B. C. (2015). Work patterns dictate energy demands and thermal strain during wildland firefighting. Wilderness Environ. Med. 26, 221-226. doi: 10.1016/j.wem.2014.12.010

Dorman, L. E., and Havenith, G. (2009). The effects of protective clothing on energy consumption during different activities. Eur. J. Appl. Physiol. 105, 463-470. doi: 10.1007/s00421-008-0924-2

DuBois, D., and DuBois, E. F. (1916). A formula to estimate the approximate surface area if height and weight be known. Arch. Intern. Med. 17, 863-871.

Gagge, A. P., and Gonzalez, R. R. (1996). "Mechanisms of heat exchange: biophysics and physiology," in Handbook of Physiology, Environmental Physiology, eds M. J. Fregly and C. M. Blatteis (Bethesda, MD: American Physiological Society), 46-84.

Gonzalez-Alonso, J., Teller, C., Andersen, S. L., Jensen, F. B., Hyldig, T., and Nielsen, B. (1999). Influence of body temperature on the development of fatigue during prolonged exercise in the heat. J. Appl. Physiol. 86, 1032-1039.

Havenith, G. (2002). Interaction of clothing and thermoregulation. Exog. Dermatol. 1, 221-230. doi: 10.1159/000068802 
Havenith, G., denHartog, E., and Martin, S. (2011). Heat stress in chemical protective clothing: porosity and vapour resistance. Ergonomics 54, 497-507. doi: 10.1080/00140139.2011.558638

Havenith, G., and Heus, R. (2004). A test battery related to ergonomics of protective clothing. Appl. Ergon. 35, 3-20. doi: 10.1016/j.apergo.2003.11.001

Holmér, I. (1985). Heat exchange and thermal insulation compared in woolen and nylon garments during wear trials. Text Res. J. 55, 511-518. doi: 10.1177/004051758505500901

Holmér, I. (2006). Protective clothing in hot environments. Ind. Health 44, 404-413. doi: 10.2486/indhealth.44.404

Holmér, I., Kuklane, K., and Gao, C. (2006). Test of firefighter's turnout gear in hot and humid air exposure. Int. J. Occup. Saf. Ergon. 12, 297-305. doi: 10.1080/10803548.2006.11076689

International Standardization Organization (ISO) (2003). Protective Clothing for Firefighters. Laboratory Test Methods and Performance Requirements for Wildland Firefighting Clothing. ISO 15384. Geneva: ISO.

Keiser, C., and Rossi, R. (2008). Temperature analysis for the prediction of steam formation and transfer in multilayer thermal protective clothing at low level thermal radiation. Text Res. J. 78, 1025-1035. doi: 10.1177/00405175080 90484

Kofler, P., Burtscher, M., Heinrich, D., Bottoni, G., Caven, B., Bechtold, T., et al. (2015). Performance limitation and the role of core temperature when wearing light-weight workwear under moderate thermal conditions. J. Therm. Biol. 47, 83-90. doi: 10.1016/j.jtherbio.2014.11.007

Kwon, A., Kato, M., Kawamura, H., Yanai, Y., and Tokura, H. (1998). Physiological significance of hydrophilic and hydrophobic textile materials during intermittent exercise in humans under the influence of warm ambient temperature with and without wind. Eur. J. Appl. Physiol. 78, 487-493. doi: 10.1007/s004210050450

Lee, J.-Y., Kim, S., Jang, Y.-J., Baek, Y.-J., and Park, J. (2014). Component contribution of personal protective equipment to the alleviation of physiological strain in firefighters during work and recovery. Ergonomics 57, 1068-1077. doi: 10.1080/00140139.2014.907449

Lotens, W. A., and Havenith, G. (1995). Effects of moisture absorption in clothing on the human heat balance. Ergonomics 38, 1092-1113. doi: 10.1080/00140139508925176

Mäkinen, H. (2005). “Firefighter's protective clothing," in Textiles for Protection, ed R. A. Scott (Cambridge, Woodhead), 622-647.

McLellan, T. M., Pope, J. I., Cain, J. B., and Cheung, S. S. (1996). Effects of metabolic rate and ambient vapour pressure on heat strain in protective clothing. Eur. J. Appl. Physiol. Occup. Physiol. 74, 518-527.

Montain, S. J., Sawka, M. N., Cadarette, B. S., Quigley, M. D., and McKay, J. M. (1994). Physiological tolerance to uncompensable heat stress: effects of exercise intensity, protective clothing, and climate. J. Appl. Physiol. 77, 216-222.

Nayak, R., Houshyar, S., and Padhye, R. (2014). Recent trends and future scope in the protection and comfort of fire-fighters' personal protective clothing. Fire Sci. Rev. 3, 4. doi: 10.1186/s40038-014-0004-0

Phillips, M., Petersen, A., Abbiss, C. R., Netto, K., Payne, W., Nichols, D., et al. (2011). Pack Hike Test finishing time for Australian firefighters: pass rates and correlates of performance. Appl. Ergon. 42, 411-418. doi: 10.1016/j.apergo.2010.08.020

Poirier, M. P., Meade, R. D., McGinn, R., Friesen, B. J., Hardcastle, S. G., and Flouris, A. D., et al. (2015). The influence of Arc-flash and fire- resistant clothing on thermoregulation during exercise in the heat. J. Occup. Environ. Hyg. 12, 654-667. doi: 10.1080/15459624.2015.1029615

Qian, X., and Fan, J. (2009). A quasi-physical model for predicting the thermal insulation and moisture vapour resistance of clothing. Appl. Ergon. 40, 577-590. doi: 10.1016/j.apergo.2008.04.022
Raimundo, A. M., and Figueiredo, A. R. (2009). Personal protective clothing and safety of firefighters near a high intensity fire front. Fire Saf. J. 44, 514-521. doi: 10.1016/j.firesaf.2008.10.007

Rodríguez-Marroyo, J. A., López-Satue, J., Pernía, R., Carballo, B., García-López, J., Foster, C., et al. (2012). Physiological work demands of Spanish wildland firefighters during wildfire suppression. Int. Arch. Occup. Environ. Health 85, 221-228. doi: 10.1007/s00420-011-0661-4

Ruby, B. C., Shriver, T. C., Zderic, T. W., Sharkey, B. J., Burks, C., and Tysk, S. (2002). Total energy expenditure during arduous wildfire suppression. Med. Sci. Sports Exerc. 34, 1048-1054. doi: 10.1097/00005768-200206000-00023

Saunders, A. G., Dugas, J. P., Tucker, R., Lambert, M. I., and Noakes, T. D. (2005). The effects of different air velocities on heat storage and body temperature in humans cycling in a hot, humid environment. Acta Physiol. Scand. 183, 241-255. doi: 10.1111/j.1365-201X.2004.01400.x

Selkirk, G. A., and McLellan, T. M. (2001). Influence of aerobic fitness and body fatness on tolerance to uncompensable heat stress. J. Appl. Physiol. 91, 2055-2063

Selkirk, G. A., and McLellan, T. M. (2004). Physical Work Limits for toronto firefighters in warm environments. J. Occup. Environ. Hyg. 1, 199-212. doi: 10.1080/15459620490432114

Sköldström, B. (1987). Physiological responses of fire fighters to workload and thermal stress. Ergonomics 30, 1589-1597. doi: 10.1080/00140138708966049

Smith, D. L., and Petruzzello, S. J. (1998). Selected physiological and psychological responses to live-fire drills in different configurations of firefighting gear. Ergonomics 41, 1141-1154. doi: 10.1080/001401398186441

Taylor, N. A. S., Lewis, M. C., Notley, S. R., and Peoples, G. E. (2012). A fractionation of the physiological burden of the personal protective equipment worn by firefighters. Eur. J. Appl. Physiol. 112, 2913-2921. doi: 10.1007/s00421-011-2267-7

Tikuisis, P., McLellan, T. M., and Selkirk, G. (2002). Perceptual vs. physiological heat strain during exercise-heat stress. Med. Sci. Sports Exerc. 34, 1454-1461. doi: 10.1097/00005768-200209000-00009

Wang, F., Gao, C., Kuklane, K., and Holmér, I. (2013). Effects of various protective clothing and thermal environments on heat strain of unacclimated men: the PHS (predicted heat strain) model revisited. Ind. Health 51, 266-274. doi: 10.2486/indhealth.2012-0073

Wegesser, T. C., Pinkerton, K. E., and Last, J. A. (2009). California wildfires of 2008: coarse and fine particulate matter toxicity. Environ. Health Perspect. 117, 893-897. doi: 10.1289/ehp.0800166

Wen, S., Petersen, S., McQueen, R., and Batcheller, J. (2015). Modelling the physiological strain and physical burden of chemical protective coveralls. Ergonomics 58, 2016-2031. doi: 10.1080/00140139.2015.1051595

Yoo, S., and Barker, R. L. (2005). Comfort properties of heat resistant protective workwear in varying conditions of physical activity and environment. part II: perceived comfort response to garments and its relationship to fabric properties. Text. Res. J. 75, 531-539. doi: 10.1177/0040517505054190

Conflict of Interest Statement: The authors declare that the research was conducted in the absence of any commercial or financial relationships that could be construed as a potential conflict of interest.

Copyright (c) 2017 Carballo-Leyenda, Villa, López-Satué and Rodríguez-Marroyo. This is an open-access article distributed under the terms of the Creative Commons Attribution License (CC BY). The use, distribution or reproduction in other forums is permitted, provided the original author(s) or licensor are credited and that the original publication in this journal is cited, in accordance with accepted academic practice. No use, distribution or reproduction is permitted which does not comply with these terms. 